\title{
Analyzing Methods to Achieve Successful Development
}

\author{
Ashley G. Thode \\ MS Candidate - Biosystems Engineering \\ Michigan State University \\ agthode@gmail.com \\ Kimberly D. Landick \\ Practicing Engineer \\ kdlandic@gmail.com \\ Kurtis G. Paterson \\ Assistant Professor, Dept. of Civil and Environmental Engineering \\ Michigan Technological University \\ paterson@mtu.edu \\ David W. Watkins \\ Associate Professor, Dept. of Civil and Environmental Engineering \\ Michigan Technological University \\ dwatkins@mtu.edu
}

\begin{abstract}
While it is easy to set worldwide development goals, achieving and meeting those benchmarks is not so simple. The goal of many nongovernmental organizations (NGOs) is to spread development to communities. Two months were spent in Arusha, Tanzania interviewing NGOs which complete projects in many disciplines ranging from water and sanitation to energy and agriculture. The NGOs were asked how they define the success of a project, about challenges encountered and lessons learned, and to discuss any monitoring strategies they may have. The interviews revealed that many organizations have not established metrics of success nor do they have well-defined procedures for evaluating their projects. This leads to a lack of focus on monitoring following the implementation of a project. However, many donor organizations and agencies have recently added monitoring and quantitative metrics of project success. The most frequently identified challenge was regarding community interaction. Community participation is a challenge for various NGOs; however, many NGOs explained that through increased community interaction success of a project amplifies. These survey results can be used as a guide for engineers interested in entering the development sector, or by those who are already involved in it.
\end{abstract}

Index Terms - international sustainable development, reflection, service learning, qualitative survey

\section{INTRODUCTION}

Development remains a concept and not a reality for ninety percent of the world's population. While most businesses, schools, and technological advances focus on the richest ten percent of people, there are some organizations that exist to serve the poorest ninety percent. These organizations are governmental, nongovernmental, and for-profit groups. ${ }^{1}$ Many of the projects these groups work on are successful, but others fail. Past studies have demonstrated that 
implemented potable water supply systems can have as high as a 70\% failure rate and shown that many development projects are non-functioning and unused. ${ }^{23}$

To identify and analyze "best practices" for successful development, ten nongovernmental organizations (NGOs) were interviewed during a two-month stay in Arusha, Tanzania in 2010. The majority of the NGOs interviewed worked to serve the sixty percent of the population of Arusha that lives below the poverty line. ${ }^{4}$ The project implementation process for each NGO was discussed; questions regarding selection of projects and participants, implementation methods, and post implementation follow-up were included. The qualitative interviews also included questions on challenges, successes, monitoring, and lessons learned. It is estimated that globally there are 25,000 NGOs, and this number keeps growing. As additional NGOs get started, it is increasingly important that these NGOs have efficient practices in order to be successful. ${ }^{5}$

\section{Objectives}

- Determine whether or not NGOs establish short and long term goals before beginning a project, how these goals are selected, and if they relate them to the term "success."

- Evaluate current monitoring standards and practices for the NGO projects.

- Gather information and advice that NGOs believe they have benefited from, including challenges and lessons learned, in order to aid other NGOs in more efficiently implementing successful projects.

\section{INTERVIEW METHODOLOGY}

The interview questions were created to allow participants to provide detailed qualitative responses using personal experiences. The goal of qualitative interviewing is to prevent guiding the subject of the interview to a specific answer. Therefore, the flow of interviews was flexible based on the conversations that arose. ${ }^{6}$ The interview questions and procedures were reviewed by the Michigan Tech Internal Review Board (IRB) to ensure confidentiality and safety of participants.

Interviews were conducted in a variety of settings, with many interviews conducted at the NGO office or project location in the Arusha area. The interviews were recorded using voice recording equipment, and afterwards the interviews were transcribed and the results were discussed and analyzed. The phrasing of interview questions and order was revised following the second interview. These adjustments took place based on responses from the initial NGOs interviewed and an increased understanding of the Tanzanian culture and interviewing methods.

\section{SUMMARY OF NONGOVERNMENTAL ORGANIZATIONS INTERVIEWED}

A variety of NGOs were interviewed. Their focuses varied but included engineering technologies, agriculture, education, vocational training, and health awareness. A description of the ten NGOs interviewed is included in Table 1, along with the title in which each NGO will be identified throughout the report. 
TABLE 1

DESCRIPTION OF NGOS

\begin{tabular}{cl}
\hline Identifier & Description of Work \\
\hline NGO 1 & $\begin{array}{l}\text { Works with environmental conservation, nutrition encouragement, and water quality in the } \\
\text { Arusha area. }\end{array}$ \\
NGO 2 & $\begin{array}{l}\text { Monitors the implementation of rural agricultural projects. Works with NGO } 3 \text { and } 5 . \\
\text { NGO } 3\end{array}$ \\
& $\begin{array}{l}\text { Works with projects in rural communities including a chicken vaccination project, } \\
\text { HIV/AIDS awareness project, and sustainable agriculture projects. }\end{array}$ \\
NGO 4 & School for orphans and disadvantaged youth. \\
NGO 5 & $\begin{array}{l}\text { Works with rural farmers to promote planting and use of jatropha seeds to obtain oil for } \\
\text { soap, cooking and lighting. }\end{array}$ \\
NGO 6 & $\begin{array}{l}\text { Provides health education to rural communities, especially focused on HIV/AIDS. } \\
\text { NGO } 7\end{array}$ Works with street children and conservation efforts. \\
NGO 8 & $\begin{array}{l}\text { Community based organization that provides housing and vocational training for young } \\
\text { women, focuses on single women with one child. }\end{array}$ \\
NGO 9 & $\begin{array}{l}\text { Works on projects with land conservation, HIV/AIDS awareness, animal research, and } \\
\text { entrepreneurial training. }\end{array}$ \\
NGO 10 & $\begin{array}{l}\text { Provide individual farmers and communities with livestock, trees, and training. They also } \\
\text { provide HIV/AIDS education to communities. }\end{array}$ \\
\hline
\end{tabular}

\section{INTERVIEW RESPONSES AND ANALYSIS}

\section{Successes}

Success is often difficult to define and can vary between projects or NGOs. However, it is vital that organizations set end goals in order to eventually determine their successes. The World Association of Non-Governmental Organizations suggests in their recommendations for starting an NGO that the first necessary step is to establish a purpose, vision, and short- and long-term goals for the organization. ${ }^{7}$ It is also important to set realistic goals, since no organization could ever solve all of the world's problems; it will take millions of small efforts. ${ }^{8}$ The survey asked participants to explain how they define success, in order to help the research team gain a better understanding of the expectations and areas of emphasis of the groups actively working on projects. This often led into discussing specific goals set by the NGO.

NGO 1 has defined success for implemented projects and also for the overall organization. Success is defined by each individual person that participates in a project. The NGO focuses on the values and benefits of impacting one person's life positively, and success is determined by observing that change. For instance, after implementing a project focused on education of women on healthy eating habits, the NGO observed a change in groceries purchased by many participants. Furthermore, while creating goals for a project the NGO actively involves the community so that participants can understand the final impacts of a project. However, NGO 1 warns that there must be a balance between the NGO's community expectations and the willingness of the community to participate in the project. Setting realistic goals for the community and thoroughly explaining project expectations, results and benefits will aid in active participation in a project. This will also prevent any "negative attitudes" that the community may eventually form.

Another way in which NGO 1 has ascertains success is through acknowledgement from governmental agencies and peers. Evidence that this NGO has completed successful projects includes multiple awards from municipal governments. Additionally, the organization has been 
invited to numerous conferences to share their story. This demonstrates that success can also be defined by influencing other groups to allow the work of one NGO to impact people beyond its original scope.

NGO 2 explained that they are better able to determine community needs and identify potential projects by conducting a baseline surveys prior to project implementation. The information obtained is then compared to a similar survey that is conducted after the conclusion of the project. The organization believes they are then able to determine whether or not the project actually met the needs of the community. NGO 2 also partners with other NGOs during projects to better utilize the strengths of each organization. The support and effectiveness of this partnership is also used to define the success of the project.

NGO 3 only recently began to measure the success of their projects. Although the organization has been established for over 15 years, monitoring is a new concept and the meaning of success had not been previously analyzed. However, a recent demand from funders has lead to a focus on quantitative results including health statistics and crop yields. NGO 3 acknowledged the benefits of setting goals, so that success can be identified, instead of following their previous generic goal: "let's help as many as we can."

While establishing quantitative goals is a new concept to NGO 3, not every NGO has embraced this as the true definition of success. NGO 4 explained that their organization is not “exactly measuring success." The NGO conducts life skills education classes, which discuss reproductive health, communication, decision making, goal setting, and other important skills. The course is based in the U.S. Peace Corps life skills curriculum. ${ }^{9}$ Even though the NGO was reluctant to define success, they did explain that at the end of each term the students complete an evaluation form. Within that form students are asked to discuss lessons that were of particular interest and lessons they will never forget. Success then can be identified by the responses of the students. NGO 4 considers a project successful "[i]f every kid can at least list one or two things that they'll never forget."

In summary, both NGOs 1 and 4 analyze the overall success of a project, and their definitions of success are driven by the impacts to the individual participants. Additionally, NGO 2 evaluates success in a similar manner, though at a community level, with success equated to fulfilling a need that the community had previously identified. For NGO 2 success is measured by conducting community surveys and evaluating the strength of partnerships. A summary table of selected interview NGO responses regarding success follows (Table 2).

TABLE 2:

SELECTED DEFINITIONS OF SUCCESS BY NGOS

\begin{tabular}{|c|c|}
\hline Identifier & Definition of Success \\
\hline NGO 1 & $\begin{array}{l}\text { The vision desired is realized. An example includes observing changes in eating habits to } \\
\text { include vegetables and other nutrients }\end{array}$ \\
\hline NGO 2 & People eat more and that the village's food insecurities diminish \\
\hline NGO 3 & $\begin{array}{l}\text { Depends on the issues being addressed but a real need must be identified, not a pre- } \\
\text { cooked idea }\end{array}$ \\
\hline NGO 4 & $\begin{array}{l}\text { Success is achieved when students retain lessons taught during class and can list the } \\
\text { gained knowledge }\end{array}$ \\
\hline NGO 5 & Adoption of the project \\
\hline NGO 6 & Community integration and education \\
\hline NGO 7 & Establishing financial independence and the street children holding jobs after graduation \\
\hline NGO 8 & The women's ability to use the life skills taught after leaving the center \\
\hline
\end{tabular}




\section{Challenges}

Numerous challenges arise throughout the implementation process for any project. However, these challenges are rarely discussed in detail. ${ }^{10}$ To expand on the existing understanding of challenges faced by NGOs, the survey included a question regarding obstacles encountered. Many lessons can be learned from analyzing challenges, and the knowledge gained can be used to avoid similar obstacles in the future.

NGO 4 explained numerous challenges that they have come across, most of them centered on cultural differences and employees not completing their assigned duties. More specifically, NGO 1 identified finding the correct participants and explaining individuals' roles as a challenge. Similarly, NGO 6 stated, "You have to find the right people, the right people who will accept the message." The project participants must understand the "motifs" and goals of the implemented project from the beginning. NGO 1 has been able to overcome this challenge by thoroughly explaining the project and integrating it into the community.

NGO 3 expressed a similar sentiment-finding the right people to take on varying roles of responsibility is crucial—and provided an example. For their chicken vaccination program they train one vaccinator in each village. There are some perks to this job, including a small stipend and access to a bicycle to complete the work. The vaccinator is selected - according to local custom - by the village leadership. There have been a few instances where the correct individual for the job was not selected, instead a relative of one of the leaders is chosen. However, they have had some extremely successful vaccinators selected. NGO 3 attributed this success to establishing their organization in the community and meeting the villagers early in the process. Then, they can offer more suggestions for which person would be the best candidate for the job.

Conducting work remotely has been a challenge for NGO 5. The communities that they serve are located outside of Arusha, which is the location of their headquarters. They frequently travel to complete field work and realize that the day they selected does not work for the village due to a holiday, funeral, or other event. This costs them money and time, delaying the success of the projects. Through establishing closer relationships and becoming more integrated with the communities, this challenge could be overcome. NGO 6 also explained that this has historically been a challenge for their organization. Consequently, they have decided to relocate to be able to have constant communication with their participants.

NGO 5 explained that implementing a project that takes three years to reach completion has presented numerous challenges. They stated that it is difficult to convince people that the project will benefit them unless there are immediate benefits to participants. Working within the agricultural sector, long time frames for projects has been particularly challenging for their organization. To overcome this obstacle, they conduct education sessions. However, they have been able to observe greater adoption of jatropha plants, which have a three-year maturity period, through introducing additional crops, such as sweet potatoes, that produce significant yields within one season.

NGO 7 explained that whenever a challenge arises they move quickly to solve and eliminate it. Although this process may work for this NGO, they do not keep any record of these challenges and methods to overcome them. This could perpetuate repeated problems if there is significant employee turnover.

The challenge that was most frequently identified by the interviewed NGOs was a lack of cultural understanding and community integration. These are two factors that are commonly identified as requirements to complete a successful project. ${ }^{11}$ Although these needs are well 
known, the challenge of assimilation and understanding perpetuates in active projects in Arusha, TZ. By carefully selecting the communities in which to complete work, and establishing close community contacts, this challenge could be greatly reduced. A summary of challenges encountered by selected interviewed NGOs is shown below (Table 3).

TABLE 3:

KEY CHALLENGES IDENTIFIED BY NGOS

\begin{tabular}{cl}
\hline Identifier & Definition of Success \\
\hline NGO 2 & $\begin{array}{l}\text { Training community members to understand capacity building and how to address people's } \\
\text { expectations }\end{array}$ \\
NGO 3 & $\begin{array}{l}\text { Realizing that the village leaders have a huge role in the projects and working with them to } \\
\text { help them make the best decisions for their communities }\end{array}$ \\
NGO 4 & $\begin{array}{l}\text { Reliability of coworkers and setting fair and official policies } \\
\text { NGO } 5\end{array}$ \\
Integration with community and gaining trust of community when working on multi-year \\
projects
\end{tabular}

Monitoring

The number of NGOs involved in development aid has increased greatly in recent years. With this growth, identifying the achievements of NGOs has been a developing concern. ${ }^{12}$ Monitoring of projects should be a regular process in development work in order to keep track of project progress and adjust the plans if necessary to improve efficiency. Effective monitoring practices can also lead to improvement in program management, strengthening of capacity building, and better alignment with the expectations of donors. ${ }^{13}$ Even though continued follow-up and monitoring of projects is stressed frequently in literature regarding development ${ }^{14}$, it has generally been difficult for organizations to reach persuasive conclusions about their work. This may be due to ambitious expectations, complexity caused by scale, activity diversity, vague objectives, or the absence of baseline data. ${ }^{15}$ The interviews contained a question regarding monitoring after a project is completed to determine if and how existing NGOs complete this stage of the development process. A few NGOs interviewed had some sort of monitoring plan in place, but many did not. It is argued that without an established presence in a community, projects will have a decreased chance of success.

NGO 8 provided a good example of monitoring. The NGO maintains contact with participants for one year after they leave the vocational center. They are required to report where they are living, their employment status, and their earnings. This allows the NGO to measure the effectiveness of their training and ensure that the graduates of their program are able to maintain healthy and successful lives. The information gained is then used to make modifications to their program. The NGO has served 167 young women in three years.

NGO 5 completes monitoring in two stages. Working in agricultural sector, the NGO establishes a three-year commitment to the community. After the three years of implementation, initial monitoring takes place. Then, three months later they return to the community to conduct the second stage of monitoring. Their focus is on adoption of the plants they introduce and use of the crops to create a means of business for the village. Expectations from donors have dictated 
the monitoring requirements. However, following the three-month follow-up there is no procedure for continued observation of the project. This NGO provides a good example, though, of how the funding institutions can use their power to encourage a successful project.

Although NGO 3 has not completed their chicken vaccination project, they have outlined their monitoring plans. However, it should be noted that this is the first time that they will be completing monitoring in this fashion. NGO 3 has established a partnership with another NGO who has a multiple-year contract to conduct interviews that span a broad range of public health topics. All villagers will be interviewed prior to the start of a project, two years later and, finally, two years after that. Although the questions will not address the project specifically, information regarding the quality of health of the participants should be evaluated, which will be used to complete the monitoring. NGO 3 explained that the partnering NGO is skilled in the monitoring process and that this will allow for the most efficient use of resources.

Conversely, NGO 6 has implemented multiple HIV/AIDS awareness campaigns; however, no follow-up has been conducted. The NGO has acknowledged the challenge of changing cultural traditions and instead focuses on education, instead of "forcing change." Although it is important that projects are not forced upon communities, this lack of structural organization has resulted in decreased funding for the NGO.

Although some NGOs provide good examples of monitoring, it was discovered that many NGOs do not complete any monitoring following an implemented project. Multiple NGOs explained that they did not know a way to measure the impacts of their work. This was especially prevalent for projects working with health or education. However, it may be concluded that having an established monitoring plan can increase funding for an NGO.

\section{Lessons Learned}

It is common for various organizations, such as USAID and the United Nations, to collect and publish "lessons learned" from different projects so that the information is available to benefit others. ${ }^{16}{ }^{17}$ Following that trend, NGOs were asked to reflect on previous projects, comment on lessons learned, and make recommendations for other NGOs. Some of the responses were project specific, while others were broad and could apply to numerous aspects of development work.

The most common lesson learned by the interviewed NGOs was the importance of integrating an organization into the community as much as possible. This is also listed as the most important operational guideline for NGOs set by KIVU Nature, Inc., a consultant in sustainable project development. ${ }^{18}$ NGOs 1, 5, 6, 7, 8, 9 and 10 all explained that it is important not to be an outsider, and that by participating in the village's daily life it is easier to complete successful projects. NGO 10 hires people who are educated outside of the village, but originally come from the tribes they serve. Additionally, NGO 5 remarked that a challenge for them is arriving in a community expecting to complete work, but finding out that it is a holiday or that there is another event taking place that prevents them from being able to promote their projects. This NGO focuses on large-scale projects--the project that was discussed in the interview has impacted over 10,000 families already. Therefore, due to the scope of the projects it is challenging for NGO 5 to have a constant presence in each community. Although nearly all of the NGOs explained that community assimilation is crucial, many of them also acknowledged challenges in completing this task. 
NGO 4 stressed that flexibility is key while completing development work, and they noted that the majority of the challenges that they had encountered were overcome by adapting and being flexible. NGO 4 also explained, in the context of a life skills class taught to secondary school children, that repetition of concepts during educational programs needs to take place. This class covers a range of topics, many of which are health-related. Through repetition, each time in new innovative ways, the students have been able to better understand and remember the material covered.

NGO 1 cited that lots of energy is crucial for a successful project. Since there is a significant amount of work associated with every project, and often a large amount of information that needs to be refined and explained to the community, energetic individuals are needed to drive the process. The NGO also cited the importance of acknowledging the value of making a difference in individual lives. However, it was observed through talking with NGO 1 that much of the work is completed by one individual. This could be problematic in the long term sustainability of projects since one person holds all of the knowledge of the projects and operations of the NGO. Additional lessons learned expressed by selected NGOs follows (Table 4).

TABLE 4:

SUMMARY OF NGO LESSONS LEARNED

\begin{tabular}{cl}
\hline NGO & Lesson Learned \\
\hline 2 & $\begin{array}{l}\text { Work with the local government as much as possible, it will allow for more to get accomplished } \\
\text { and establish efficient lines of communication }\end{array}$ \\
3 & $\begin{array}{l}\text { Integration into the community is crucial, work together with community to establish leaders of } \\
\text { the project }\end{array}$ \\
3 & $\begin{array}{l}\text { Adapt your project as you go based on the community's needs } \\
\text { If a project is long term, short term projects are also necessary in order to encourage community } \\
\text { members and earn their trust }\end{array}$ \\
7 & $\begin{array}{l}\text { Strict discipline is important and making sure everything is locked so that stealing is not an issue } \\
\text { (speaking about a boy's school) }\end{array}$ \\
\hline
\end{tabular}

\section{IMPlications for SERVice LeARNing Programs}

Many organizations can benefit from the knowledge gained from these interviews with ten NGOs. The organizations include Engineers Without Borders-USA, Engineers for a Sustainable World, and other student and professional groups. This information should be used to promote more effective communication and partnerships between these groups and NGOs.

First, it is vital that the partnering NGO has a strong presence in the community in which the project will take place. Since time in-country for service learning groups is often short, the NGO's responsibilities should include understanding the community and establishing a strong relationship with community leaders. Since the most valuable lessons learned and responses to challenges faced involve community interaction, this point is essential. If a service learning group is not able to form an appropriate partnership, with an NGO or other community organization, a different project should probably be sought, unless the group is prepared to devote substantial time towards gaining community understanding and respect.

Next, if a project needs to take place over a long time span, such as with the Jatropha project, other smaller projects should be implemented in the same communities that can produce results 
more quickly, such as within a few months or within a single growing season. The community will have more faith in the long-term project, and they will be more likely to respect the knowledge of the service learning program participants, thus increasing the prospects of success.

Setting measurable goals is another important aspect of achieving successful development. These goals should be both quantitative and qualitative. Additionally, in order to evaluate whether the goals were achieved, monitoring must be completed over an appropriate amount of time (varies dependent on the project). Measuring the influences of a project, such as by evaluating design performance and health impacts, will allow future projects to be completed more efficiently.

Overall, two of the most important skills to utilize in a project are communication and flexibility. Service learning programs should be able to communicate effectively with an NGO and the community they are working in. They should also have the ability to be flexible in every part of the project, including assessment, implementation, and monitoring. By taking into consideration communication, flexibility, and the other lessons learned, the prospect of a project's success will greatly increase.

\section{CONCLUSION}

After conducting ten interviews with development NGOS, a greater understanding of methods to achieve successful development has been gained. While some organizations were hesitant to openly discuss sensitive issues such as challenges encountered, others candidly explained the specific challenges that have plagued their organizations and ways they have attempted to overcome them.

The most significant observation following the interviews is that many NGOs do not adequately reflect on the projects that they conduct. Those that do complete monitoring frequently have added this step in their projects only due to pressures from donors. This lack of monitoring was also linked to a lack of goal setting at the initial stages of a project. By establishing a defined direction for a project, communities may be better engaged, and more people will likely be served. Additionally, by documenting challenges and successes, organizations will e able to troubleshoot common problems and have a greater chance of achieving success in future projects.

Success is an elusive concept that can be defined in many ways. However, NGOs frequently used common words, including "health", “community”, and "individual”, which indicates that success must be assessed quantitatively as well as qualitatively since these attributes require an in depth understanding of community impacts. This has presented many challenges to the NGOs interviewed, which frequently do not set measurable goals or complete follow-up monitoring of projects. However, by establishing goals and a strong presence in a community, by being flexible and adapting to change, and by including a strong monitoring program in every project, many of the challenges faced by the NGOs may be overcome. It is hoped that by reflecting on the experiences of practicing NGOs working in the development field, successful development projects can be more easily attained.

\section{ACKNOWLEDGMENT}

This material is based upon work supported by the National Science Foundation under Grant No. OISE-0854050. The authors are grateful to the NGOs that participated in this study. Dr. Kari 
Henquinet, Professor of Social Sciences at Michigan Technological University, provided helpful advice for survey development. Opinions, findings, conclusions and recommendations expressed in this material are solely those of the authors.

\section{REFERENCES}

${ }^{1}$ Cooper-Hewitt, National Design Museum. Design for the Other 90\%. 2010. http://other90.cooperhewitt.org/ (accessed September 22, 2010).

${ }^{2}$ Mackintosh, G. and C. Colvin. Failure of Rural Schemes in South Africa to Provide Potable Water. Environ. Geo. 44, 101. 2003.

3 Sutton, S. Preliminary Desk Study of Potential for Self Supply in Sub-Saharan Africa. UK SC: Wateraid and the Rural Water Supply Network. 2004.

${ }^{4}$ Africa, ACE. Arusha District. 2008. http://www.ace-africa.org/index.php?page=arusha-district (accessed August 18, 2010).

${ }^{5}$ Kelly, Jocelyn. "When NGOs beget NGOs: Practicing Responsible Proliferation." The Journal of Humanitarian Assistance, 2009.

${ }^{6}$ Turner, III, Daniel W. “Qualitative Interview Design: A Practical Guide for Novice Investigators.” The Qualitative Report, 2010.

7 Moshman, Joanna. "How to Start an NGO." WANGO: World Association of Non-Governmental Organizations. 2010. http://www.wango.org/NGONews/July08/HowToStartAnNGO.pdf (accessed September 22, 2010).

${ }^{8}$ Bisoux, Tricia. "Taking Care." BizEd, 2010: 20-24.

9 Peace Corps. "Life Skills Manual." http://multimedia.peacecorps.gov/multimedia/pdf/library/M0063 lifeskillscomplete.pdf. (accessed Dec. 10 2010)

10 Anderson, Jock R. "Risk in Rural Development: Challenges for managers and policy makers." Agricultural Systems, 2003: 161-197.

11 Moshman, Joanna. "How to Start an NGO." WANGO: World Association of Non-Governmental Organizations. 2010. http://www.wango.org/NGONews/July08/HowToStartAnNGO.pdf (accessed September 22, 2010).

12 Davies, Rick. Monitoring and Evaluating NGO Achievements. Cambridge, UK: Monitoring and Evaluation News, 2000.

13 UNICEF. "A UNICEF Guide for Monitoring and Evalulation, Making a Difference?" UNICEF. http://www.unicef.org/reseval/index.html (accessed September 22, 2010).

14 Fogelberg, Kate. "Filling the knowledge gap: Monitoring post-construction water and sanitation sustainability.” Waterlines: Vol. 29 No. 3, 2010.

15 Davies, 2000.

16 Council, United Nations Economic and Social. "The National Development Strategy, Tanzania." United Nations. 2008. http://webapps01.un.org/nvp/frontend!policy.action?id=424\&tab=analysis (accessed September 28, 2010).

17 Program, Capable Partners. "Lessons Learned: The Evolution of NGO Networks in Conflict-Affected Environments." USAID/PVC-ASHA. http://pdf.usaid.gov/pdf_docs/PNADM801.pdf (accessed September 28, 2010).

18 KIVU: Knowledge, Imagery, Vision, and Understanding. "Guidelines for Non-Governmental Organizations." 2010. http://www.kivu.com/wbbook/ngoguides.html (accessed September 28, 2010). 